\title{
ON THE MAJOR FACTORS AFFECTING GOSS TEXTURE DEVELOPMENT IN GRAIN ORIENTED SILICON STEEL
}

\author{
P. GANGLI*, J. SZPUNAR* and F. GOLINI** \\ *Department of Mining and Metallurgical Engineering, \\ McGill University, Montreal, H3A 2A7,Canada \\ **DOFASCO, Electrotechnical Steel Research Laboratory \\ Hamilton, Ontario, L8N 3J5
}

\section{INTRODUCTION}

Ever since Goss discovered the method of making 'grain-oriented' silicon steel,1, a high number of explanations have been proposed. May and Turnbull2 showed that the second phase particles, particlarly MnS influence the mobility of the boundaries. Later Misra, Därman and Lücke ${ }^{3}$, as well as Inokuti4 found a strong correlation between the strength of the Gosscomponent measured in the subsurface of the hot band and that of the final product. Evidence was also given to indicate that the final Goss texture formation may also occur when the hot band subsurface contained no Goss at all5.

Haratani and Hutchinson 6 , on the other hand, based on a series of sectioning experiments of silicon steel taken at various stages between primary recrystallization and subsequent abnormal grain growth, found that shear bands of $\{111\}<112>$ orientation serve as nuclei for the Goss texture formation in the primary recrystallized specimen. Another series of research by Harase and coworkers ${ }^{7}$ followed the idea of Aust and Rutter 8 , that boundaries with a high number of coincidence site lattice points migrate with a rate higher than others. First Harase et al. 6 then Rouag et al. 9 have observed that the formation of a well aligned Goss texture with little scatter, observed after abnormal grain growth, can be linked to the $\Sigma(9)$ type CSL boundaries in the primary recrystallized structure.

For some time it was evident that it is not possible to accept several differring and contradictory explanations for the same final texture development, unless these theories are rather complementary then contradictory. We shall, in this paper, show that linking the hypotheses stated above can contribute to the understanding of the final texture development in GO silicon steel. 


\section{EXPERIMENTAL}

A complete process-flow investigation was carried out using an industrial source material of CGO quality. The processing steps were made according to standards accepted in the silicon steel industry, applicable for $0.22 \mathrm{~mm}$ materials. This involved a hot rolling, a two stage cold rolling with intermediate anneal in between and after the second cold rolling a decarburization and recrystallization anneal at $800^{\circ} \mathrm{C}$ for 2 minutes in wet hydrogen. This was followed by a 24 hour high temperature anneal at $1150^{\circ} \mathrm{C}$ in dry hydrogen and thermal flattening. Texture measurements were made by the X-ray diffraction technique. A Co-anode, source was used to measure (110), (200) (112) pole figures by reflection (from $a=0^{\circ}$ to $80^{\circ}$ ). ODFs were calculated by means of series expansion using Bunge's method 10 . The ODFs were then ghost corrected using the method of Lücke et al.11 by means of texture modeling and the corrected 'true' ODFs were used for further analysis. Texture measurements were also coupled with microstructural determination, and scanning electron microscopy (SEM) to obtain information on the second phase $\mathrm{MnS}$ morphology.

The present paper deals with the hot band stage, the primary recrystallized stage and with the final product. A more detalied analysis of the complete process flow will be published separately12. Material qualities, characterized as 'good' (Series 'A') and 'average' (Series 'B') are separately analyzed.

Characteristic ODFs for the hot rolled material, measured at the subsurface (at relative through thickness height $S=0.75$ ) are given in Figs 1a and b corresponding to 'good' (Fig. 1a) and 'average' (Fig 1b). 'Good' and 'average' refer to qualities in the final specific power loss as measured by the standard $25 \mathrm{~cm}$ Epstein probes. We note a very strong Goss texture both materials.

The textures of the final products are shown in Figs. $2 a$ and $b$. We note again the sharp Goss texture in both materials, although for ' $A$ ' the Goss peaks are twice as strong as for 'B'.

\section{THE STRUCTURE MEMORY PHENOMENON}

The influence of the Goss component in the subsurface of the hot band w.r.p. to the develoment of texture after secondary recrystallization (abnormal grain growth) can be asessed from Figs. 3a-c showing the relationship between the parameters characterizing the Goss component in the final product and the volume of the Goss component in the hot band subsurface layer. First Fig. 3a. shows ODF values for the Goss position in the final product, Fig. 3b. shows the width/scatter about RD in degrees, while Fig. 3c. gives the volume percent of the final Goss component. Corresponding values are listed in Table 1. We note that a stronger Goss component in the subsurface of the hot band leads to a stronger and sharper Goss in the final product. 
Figure 1 ODFs for the hot rolled material, obtained from subsurface texture measurments.

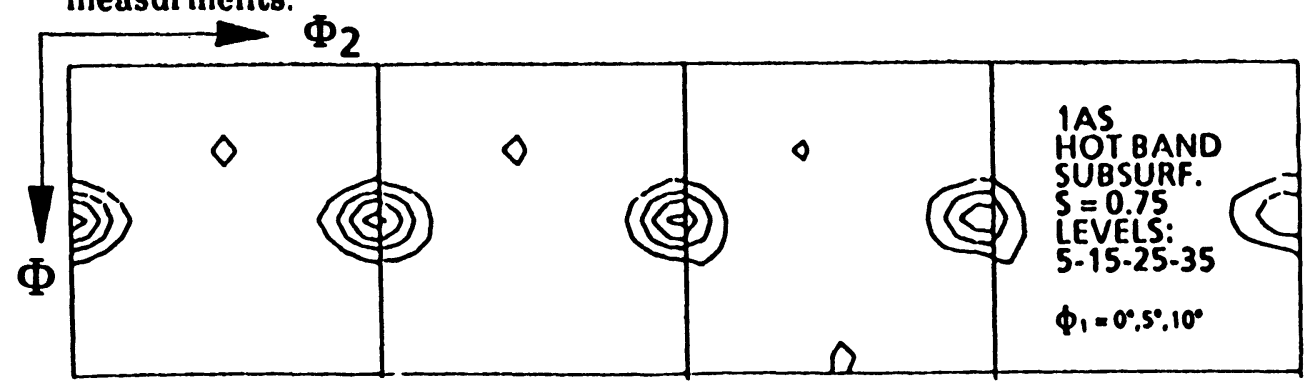

Figure 1a 'Good' (series 'A') quality.

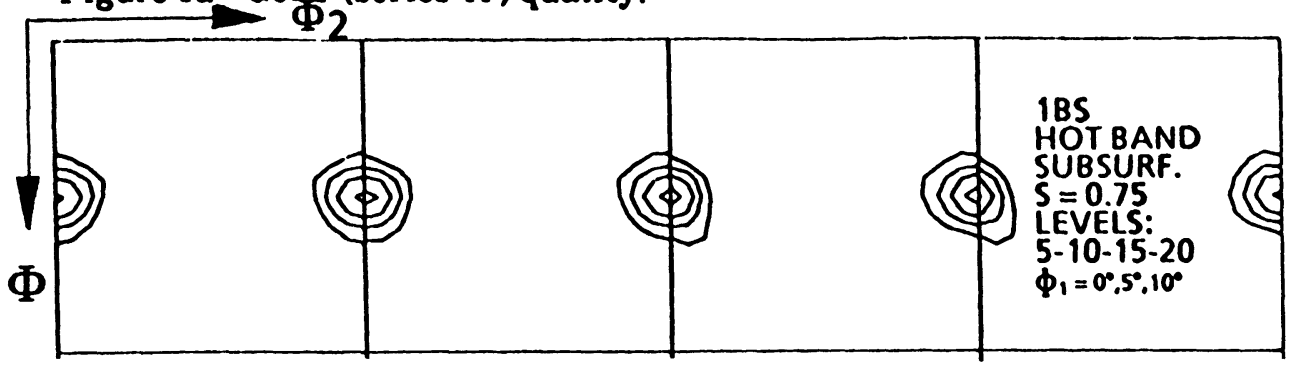

Figure 1b 'Average' quality (series 'B').

Figure 2 ODFs obtained from measurements taken after the final heat treatment (abnormal grain growth).

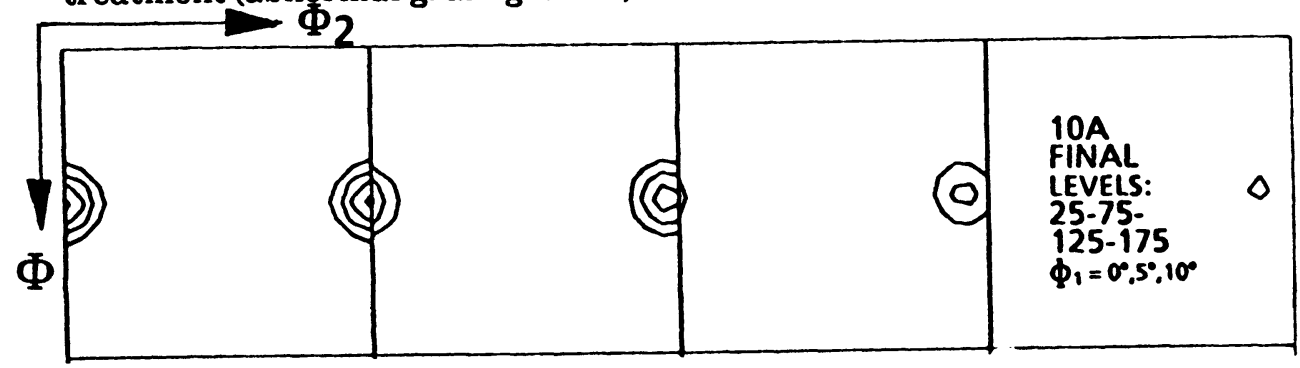

Figure 2a 'Good' (series 'A') quality.

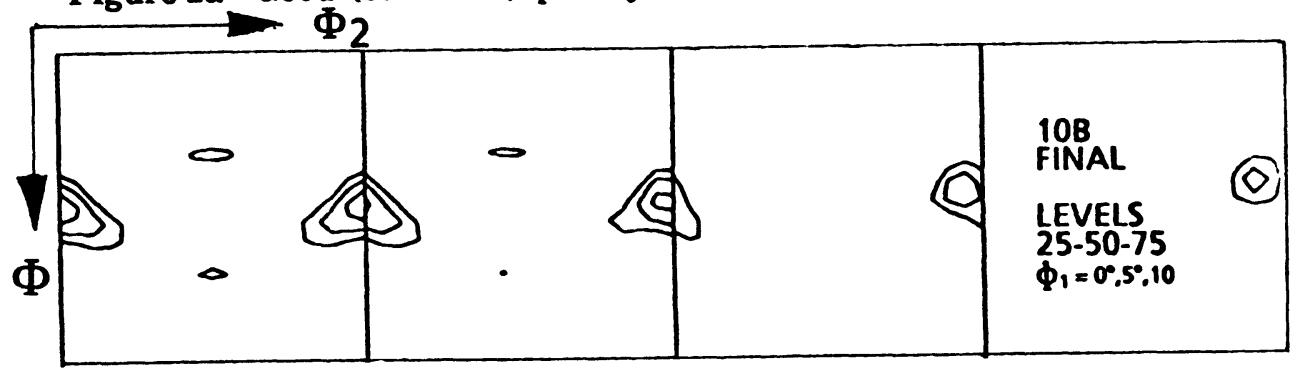

Figure 2b 'Average' (series 'B') quality. 
Figure 3a-c Functions of the volume percent of the (111) $<001>$

(Goss) component in the hot band subsurface at $S=0.75$ relative height.

Figure 3a ODF values for the Goss position in the final product.

Figure 3b Width/scatter about RD in degrees.

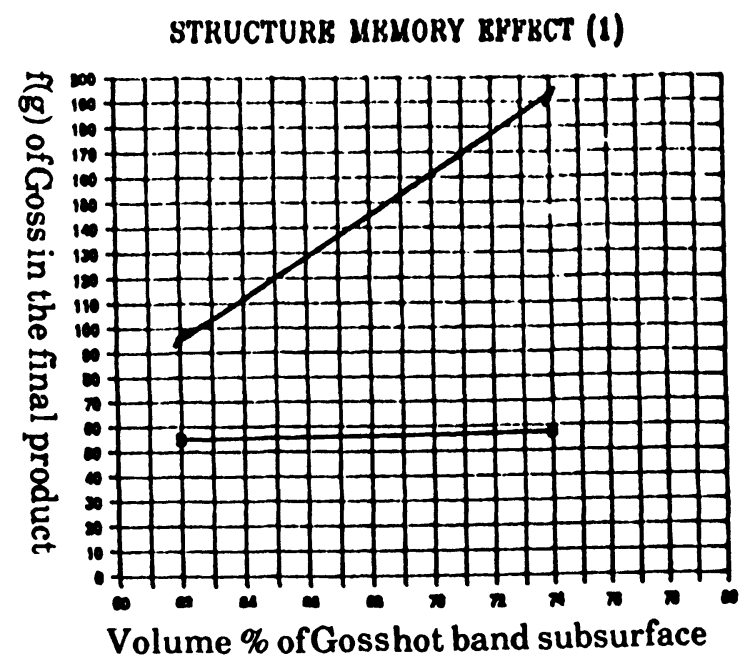

STRUCTURE YRYORY EIFPCT (2)

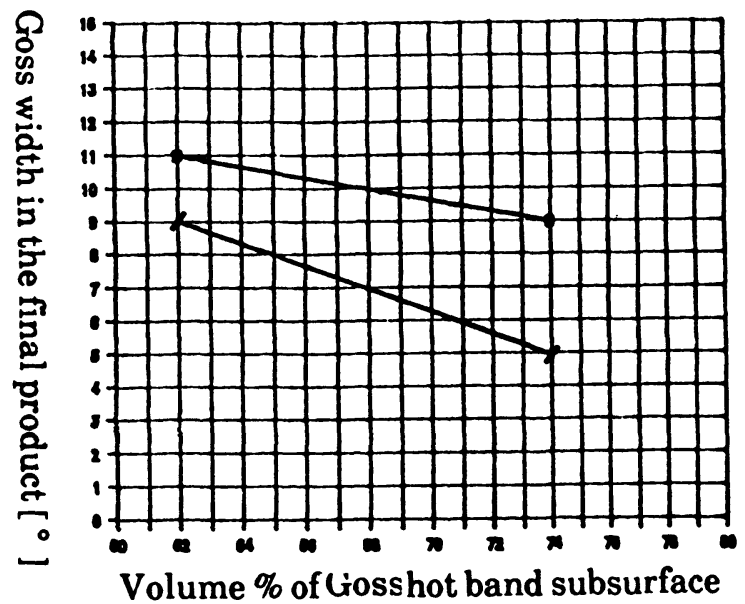

STRUCTURB YRYORY BPFBCT (5)

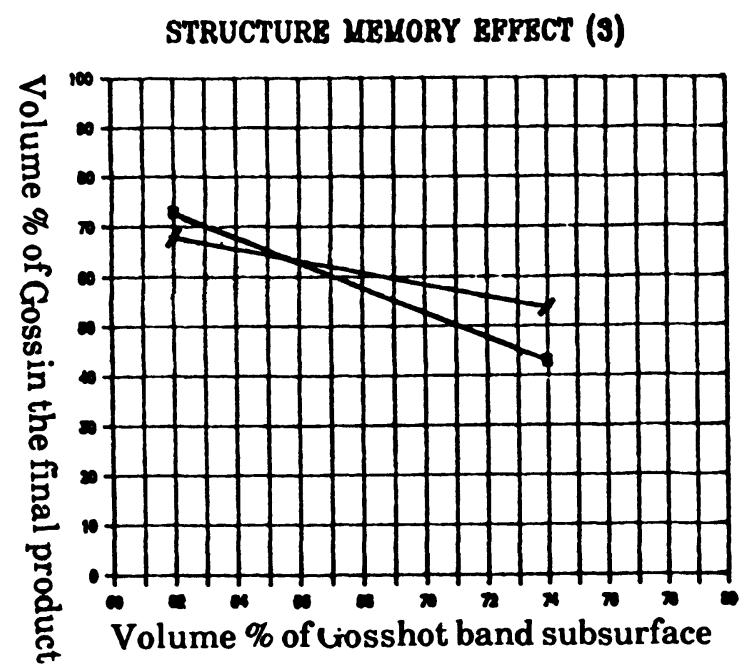

Figure 3c Volume percent of the final Goss component. 
Table 1 The influence of the hot band subsurface texture on the final

Goss texture development

\begin{tabular}{|c|c|c|c|}
\hline \multirow{2}{*}{ Material } & \multicolumn{2}{|c|}{ Structure Memory Effect } & Width/Scatter \\
& f(g) Goss & Volume \% Goss & \\
\cline { 2 - 4 } & & & \\
\hline $\begin{array}{l}\text { Hot Band } \\
\text { S=0.75 }\end{array}$ & & & \\
1AS & 41.2 & 74 & 12 \\
1BS & 22.8 & 62 & 15 \\
\hline Final Product & & & \\
9A1 & 57.6 & 43 & 9 \\
9B1 & 55.1 & 73 & 11 \\
10A & 193.2 & 54 & 5 \\
10B & 96.1 & 68 & 9 \\
\hline
\end{tabular}

\section{¿(9) CSL BOUNDARIES IN THE PRIMARY MATRIX}

The texture after primary recrystallization and decarburizaton is shown in Figs. $4 a$ and $b$ at a relative through thickness height of $(S=0.75)$. We find that the textures ' $A$ ' and ' $B$ ' are different at the $S=0.75$ relative height. These results are also represented in the form of fibres. Fibres representing the ODF values with $\{111\}$ crystallographic planes parallel to the plane of the sheet ( $\mathrm{Y}$ fibres) are shown for the primary recrystallized specimens in Fig. 5. The $\mathrm{Y}$-fibre contains the $\{111\}<112>$ orientation, which is significant in determining the probability of the $\Sigma(9)$ boundaries, favourable for the growth of Goss oriented grains.

The functional relationships correlating the probabilities of existence of $\Sigma(9)$ CSL boundaries in the primary recrystallized specimens and the Goss texture in the final product following secondary recrystallization are shown in Figs. $6 a$ to c. $\Sigma(9)$ CSL boundaries were taken as proportional to the product of the probable occurrance of the $\{111\}<112>$ component and the Goss component, allowing for a scatter of $15^{\circ}$ for the Gaussian distributions representing these components in the texture. Fig. 6a. shows F(g) ODF values of the Goss position in the final product, Fig. 6b. relates Goss width/scatter in degrees taken from $R D$, and finally $6 c$ shows the volume percent of the Goss component, all as functions of the probability of existence of $\Sigma(9)$ CSL boundaries in the subsurface of the primary 
Figure 4a, b The ODFs after primary recrystallization and decarburizaton shown at a relative through thickness height of $(S=0.75)$.

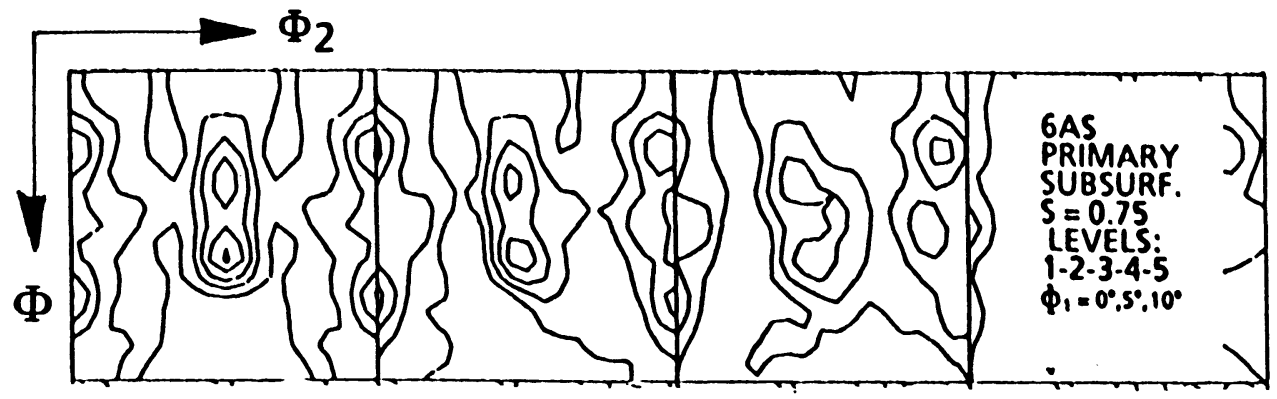

Figure 4a 'Good' (series ' $A$ ') $S=0.75$ relative height.

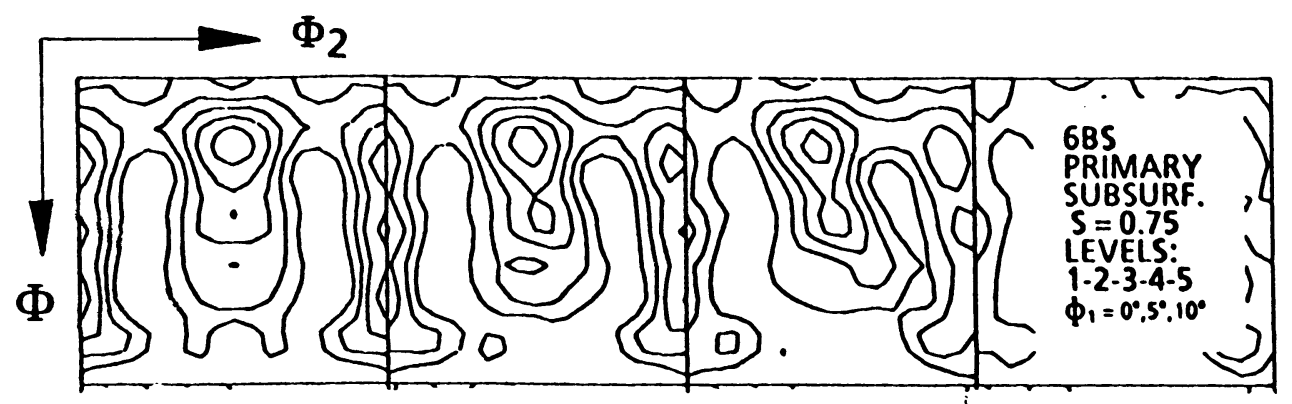

Figure 4b 'Average' (series 'B') $S=0.75$ relative height.

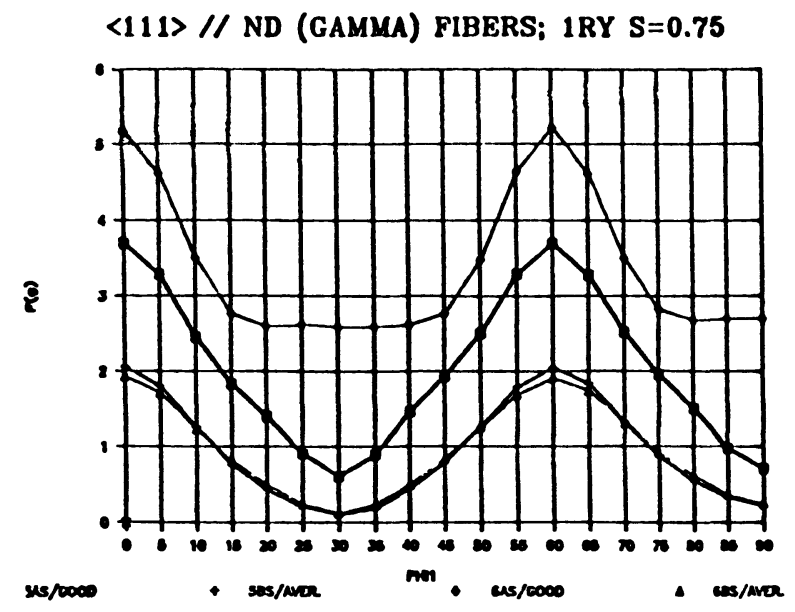

Figure 5 Fibres representing the ODF values with $<111>$ crystallographic planes parallel to the plane of the sheet ( $y$ - fibres) taken from texture measured in the primary recrystallized specimens at $S=0.75$ relative height. 
Figures. 6a to $\mathrm{c}$ Functions of the probability of existence of the $\Sigma(9)$ CSL boundaries in the primary matrix as related to:

Figure 6a $\quad F(g)$ values of the Goss position in the final product.

Figure 6b Goss width/scatter in degrees in the final product.

Figure 6c Volume percent of the Goss component in the final product.
THE BFFBCT OF CSL S(0) BOUNDARIBS (1)

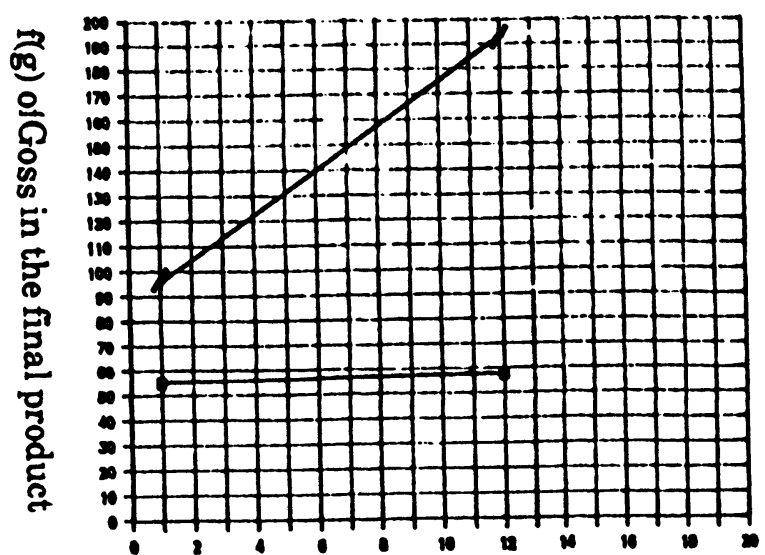

Probability of $\Sigma(9)$ boundaries primary. $s=0.75$

THE BFTBCT OP CSL S(9) BOUNDARIRS (2)

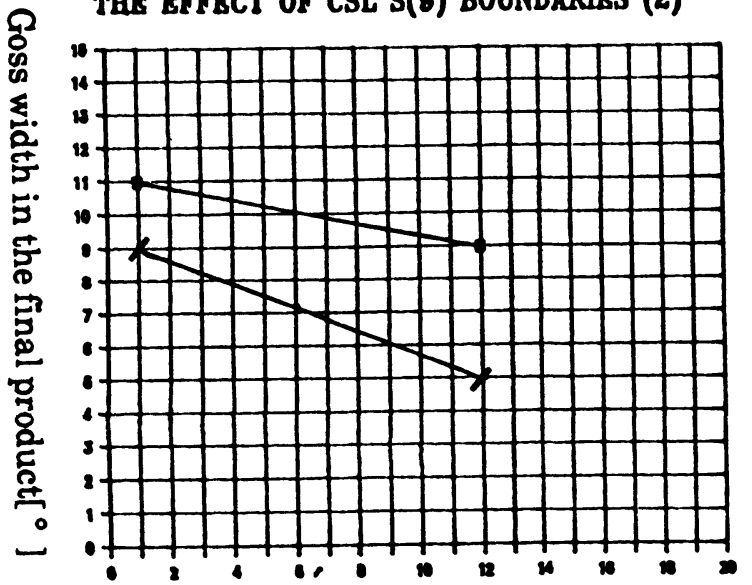

Probability of $\Sigma(9)$, boundaries primary. $s=0.75$

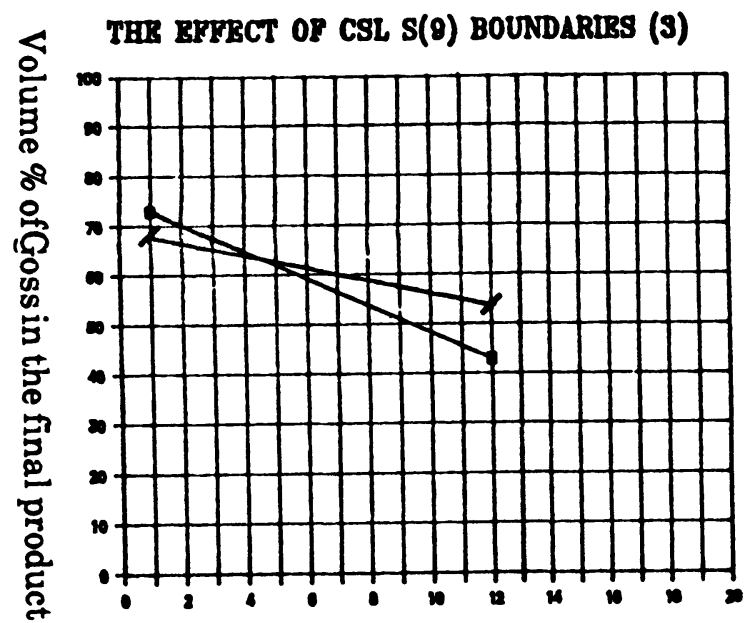

Probability of $\Sigma(9)$ boundaries primary. $s=0.75$ 
recrystallized material. The amount of CSL boundaries in the subsurface $(\mathrm{S}=0.75)$ clearly play a role in determining the strength of the Goss of the final product. These values are given again in Table 2. Materials 5A, 5B and $9 A, 9 B$ are from two separate series of experiments.

Table 2 The Influence of the $\Sigma(9)$ CSL Boundaries on the final Goss texture development

\begin{tabular}{|c|c|c|c|c|}
\hline Material & $\begin{array}{c}\Sigma(9) \text { CSL } \\
\%\end{array}$ & $\begin{array}{c}\text { Goss } \\
\mathrm{f}(\mathrm{g})\end{array}$ & $\begin{array}{c}\text { Goss } \\
\text { V \% }\end{array}$ & $\begin{array}{c}\text { Width/Scatter } \\
{\left[{ }^{\circ}\right]}\end{array}$ \\
\hline $\begin{array}{l}\text { Primary } \\
\text { Recryst. } \\
\text { S=0.75 }\end{array}$ & & & & \\
5AS & 12 & 4.51 & 9 & 13 \\
5BS & 1 & 4.10 & 5 & 12 \\
6AS & 13 & 3.13 & 4 & 14 \\
6BS & 1 & 4.43 & 5 & 9 \\
\hline Final & & & & \\
Product & & & & 9 \\
9A1 & 1 & 57.6 & 43 & 11 \\
9B1 & 1 & 55.1 & 73 & 5 \\
10A & 2 & 193.2 & 54 & 98 \\
10B & 1 & 96.1 & 68 & \\
\hline
\end{tabular}

\section{DISSCUSSION}

We have followed different approaches to explain the development of the Goss texture after abnormal grain growth. Our results indicate that both the $\Sigma(9)$ CSL boundaries in the primary recrystallized matrix, as well as the Goss component in the hot band subsurface influence the final texture development. Altough the attempt to link these two theories seems to be in its preliminary stage, our experiments suggest that such texture development routes are to be found where we can establish a link between the texture of the hot band subsurface and that of the primary recrystallized material. Although a coherent model accounting for intermediate, and final stages of texture development would be more appealing, it is indeed doubtful, how we can link a texture component in the hot band subsurface to the primary matrix. We also remember that the material goes through two cold rollings and two anneals in between. Nevertheless, it cannot be excluded that the inheritance of the Goss from the hot band leads to such components in cold rolling that helps to increase the CSL boundaries to the 
Goss orientation. Current deformation and recrystallization models cannot follow this with sufficient acccuracy, however, a series of suitable experiments, similar to those made to support 3,4 and refute 5 the structure memory phenomenon could also be useful.

\section{CONCLUSIONS}

1. Both hot band subsurface and primary recrystallized matrix structure seem to play a role in influencing the quality of the final abnormal grain growth texture in grain oriented silicon steel.

2. The linkage between the hot band subsurface and the final texture, as well as that of the $\Sigma(9)$ CSL boundaries on the final abnormal grain growth texture development in Fe-3\%Si has been shown.

3. That these factors alone can also lead to the development of sharp Goss orientation in the final texture does not exclude the occurrance of either one of these phenomenae.

4. The conditions that finally lead to the dominance of one or the other influences should be further investigated.

\section{ACKNOWLEDGEMENTS}

The financial support of DOFASCO Steel Coompany and that of the Natural Sciences and Reserarch Council of Canada is gratefully acknowledged. We also thank Dr.J. Hirsch and Professor K. Lücke for permission to use the ODF ghost correction model program.

\section{REFERENCES}

1. N.P. Goss, Trans. ASM, 23, 511 (1935).

2. J.E. May and D. Turnbull, Trans. AIME, 212, p. 769 (1958).

3. S. Misra, C. Därmann and K. Lücke, Acta metall.,32, p. 2185 (1984).

4. Y.C. Inokuti, C. Maedo, Y. Ho, Trans. ISIJ, 27,pp. 139-144 (1984).

5. H.G. Lee, K. Lücke, Proceedings of ICOTOM 8, eds. J.S. Kallend, G. Gottstein, p. 643 (1987).

6. T. Haratani, W.B.Hutchinson, I.L. Dillamore and P. Bate, Met. Sci. 18,57 (1984).

7. R.Harase, R. Shimizu, T. Watanabe, Proc. 7th Int. Symp. of Metallurgy and Mat. Sci., eds. N. Hansen, T. Leffers, B. Ralph, pp. 343-348, Riso (1986).

8. K. Aust and J.W. Rutter, Trans. AIME, 215, p. 820 (1959).

9. N. Rouag and R. Penelle, Textures and Microstructures, 11, pp. 203217 (1989).

10. H.J. Bunge, Mathematische methoden der Texturanalyse, Akademie Verlag, Berlin, (1969).

11 K. Lücke, J. Pospiech, K.H. Virnich and J.Jura, Acta metall.,29, p.167, (1981).

12. P. Gangli, J. Szpunar, F. Golini to be published. 